\title{
МЕТОДОЛОГИЯ РАЗРАБОТКИ ПАТЕНТНЫХ ЛАНДШАФТОВ ПРОЕКТНОГО ОФИСА ФИПС
}

\author{
Олег ЕНА, Николай ПОПОВ
}

Рассмотрена методология разработки отраслевых патентных ландшафтов, являющихся комплексным инструментом определения научно-технологических приоритетов и исследования конкурентоспособности перспективных технологий, продуктов и сервисов.

\section{ВВЕДЕНИЕ}

Технологическое развитие современных компаний в условиях экстремально высокой интенсивности появления новых технологий предъявляет повышенные требования к определению и своевременной корректировке научнотехнологических приоритетов, оценке конкурентоспособности перспективных российских технологий, определению стратегий вывода отечественной инновационной продукции на глобальные рынки, а также поиску бизнес- и технологических партнеров.

Важным источником информации для получения объективных сведений о текущем состоянии и направлениях развития перспективных областей научно-технологического и инновационного развития секторов экономики является патентная информация: сведения о выданных патентах, поданных заявках, областях

Ключевые слова: патентный ландшафт, патентная аналитика, менеджмент технологий, патентные исследования, научно-техническая политика, бизнес-анализ, управление инновациями приоритетов, стратегиях охраны и других аспектах патентной защиты перспективных технологий и инновационной продукции.

Анализ патентной информации обеспечивает возможность многоаспектного анализа групп перспективных технологий, инновационных продуктов и услуг по целому ряду оснований, в том числе сведений правового характера.

Использование патентной аналитики на стратегическом уровне обеспечивает объективную среду определения ключевых направлений технологиче- ского развития перспективных рынков, а на операционном уровне позволяет создать экспертно-аналитическую инфраструктуру для формирования и мониторинга выполнения портфелей крупных проектов в привязке к конкретным технологическим приоритетам компании.

Патентная информация является наиболее ценным и объективным источником для информационно-аналитической поддержки процессов управления в сфере технологий и инноваций, в том числе при решении целого ряда задач:

$\rightarrow$ выбор направлений инвестирования в технологии, поиск новых областей применения технологий;

$\rightarrow$ оценка потенциала и конкурентоспособности продукции, предполагаемой к выводу на российские и зарубежные рынки;

$\rightarrow$ оценка технологического потенциала и патентной емкости результатов интеллектуальной деятельности, предполагаемых к получению в рамках НИОКР;

$\rightarrow$ анализ областей компетенций зарубежных компаний в области приоритетов российских компаний.

Комплексным инструментом экспертно-аналитической поддержки указанных направлений является так называемый патентный ландшафт - результат масштабного аналитического исследования патентных документов и научнотехнической литературы в тесной при- 
вязке к отраслевым технологическим приоритетам, портфелям НИОКР и ключевым инновациям современных компаний.

В состав патентного ландшафта входят разнообразные аналитические представления, в том числе тренды и области интенсивного патентования, области высокой технологической конкуренции, монополизации, открытые патентные сегменты, а также профили ведущих патентообладателей и авторов изобретений. Патентный ландшафт может быть разработан как для широкой тематической области, так и для узкоспециализированной тематики.

В рамках патентного ландшафта выполняется масштабное исследование конкурентоспособности перспективных технологий, продуктов и сервисов, предполагаемых к выводу продукции на ключевые рынки.

Согласованная разработка патентных ландшафтов в рамках альбома обеспечивает системный анализ междисциплинарных технологий, продуктов и услуг, возникающих на стыках технологических направлений.

Важным элементом патентных ландшафтов является исследование положения отечественных предприятий в производственных цепочках создания стоимости, потенциала импортозамещения в части продуктов и сервисов, предполагаемых к выводу на российские рынки.

В рамках проработки патентных ландшафтов могут быть выявлены перспективные направления сотрудничества образовательных и научных организаций, производственных предприятий, центров исследований и разработок, центров трансфера технологий, бизнес-инкубаторов, малых инновационных предприятий, обладающих компетенциями в заданных технологических направлениях.

Всемирная организация интеллектуальной собственности (ВОИС) создала собственную методологию разработки патентных ландшафтов, определяющую основные принципы и техники сбора, анализа и визуализации данных в составе типового патентного ландшафта [1]. На основе методологии ВОИС Роспатентом в 2016 году разработаны Методические рекомендации по подготовке отчетов о патентном обзоре (патентный ландшафт) [2], утвержденные приказом Роспатента № 8 от 23 января 2017 года.

Вместе с тем практика проектного офиса Федерального института промышленной собственности (ФИПС) по применению патентных ландшафтов в интересах российских коммерческих компаний выявила необходимость существенной коррекции представленных методологий и рекомендаций в целях более акцентированной направленности результатов патентного ландшафта на конкретные цели и приоритеты компании.
Помимо этого, в целях более полного охвата потребностей корпоративных заказчиков целесообразно дифференцировать патентные ландшафты по уровню детализации технического анализа и вовлечения отраслевых экспертов, выделив в независимые аналитические исследования:

$\rightarrow$ экспресс патентные ландшафты, более приближенные к общепринятым методологиям;

$\rightarrow$ отраслевые патентные ландшафты, предполагающие более глубокую проработку модели предметной области и многоуровневое привлечение нескольких групп экспертов: бизнес-аналитиков, патентных экспертов, высококвалифицированных внешних экспертов.

Отраслевые патентные ландшафты предполагают детальный технический анализ по более чем 100 технологическим направлениям и масштабную экспертную интерпретацию всех графиков, диаграмм и других форм аналитических представлений.

Несмотря на существенные различия экспресс и отраслевых патентных ландшафтов, методология разработки патентных ландшафтов проектного офиса ФИПС имеет общие этапы и характеристики. Далее в настоящей статье представлено описание основных этапов разработки и ключевых аналитических представлений патентных ландшафтов, разрабатываемых по собственной методологии проектного офиса ФИПС, апробированной в ходе реальных консалтинговых проектов по широкому спектру тематических областей. В силу более сильной специфики отраслевых патентных ландшафтов при описании этапов разработки делается акцент на особенности отраслевых патентных ландшафтов, хотя методология предполагает ее применение и для экспресс патентных ландшафтов.

Определение «патентный ландшафт» в тексте ниже относится к отраслевому патентному ландшафту. В случае описания особенностей для экспресс патентного ландшафта, в тексте содержится явное упоминание вида патентного ландшафта.

\section{МЕТОДОЛОГИЯ РАЗРАБОТКИ ПАТЕНТНЫХ ЛАНДШАФТОВ}

\section{Общие сведения}

Для максимальной проработки собственной методологии проектного офиса ФИПС были проведены масштабные аналитические исследования существующих способов и методов разработки патентных ландшафтов ВОИС, патентных ведомств Великобритании, Австралии, Швейцарии и др., а также зарубежных коммерческих компаний, предоставляющих услуги по разработке патентных ландшафтов. Результаты исследования были адап- 
тированы для применения их в интересах развития инновационной системы России.

Методология включает этапы формирования патентных ландшафтов: разработку модели предметной области, систематизацию данных, отраслевую экспертизу, аналитическую обработку коллекций патентных документов, валидацию результатов и т.д. Особое место в методологии уделено взаимодействию с заказчиком на всех этапах жизненного цикла создания патентного ландшафта.

Важным аспектом методологии в применении к отраслевым патентным ландшафтам является углубленная проработка процессов и результатов, связанных с отраслевой патентной экспертизой. Для всех видов полученных аналитических результатов в рамках методологии ФИПС предусмотрено использование трех уровней экспертизы:

$\rightarrow$ бизнес-аналитиков;

$\rightarrow$ отраслевых экспертов ФИПС;

$\rightarrow$ высококвалифицированных внешних экспертов.

Такой подход обеспечивает повышенное качество проработки патентного ландшафта, дополнение его содержательными экспертными выводами, важными для практического применения патентных ландшафтов как на уровне формирования стратегии развития технологического направления, так и в операционной деятельности при формировании и контроле исполнения портфелей высокотехнологичных исследований и разработок.

Использование единой методологии позволяет унифицировать разработку патентных ландшафтов для разных отраслевых тематик и легко масштабировать ее сложные процессы: анализ патентных семейств, технический анализ исследуемой области, работу с отраслевыми экспертами и др. Таким образом, в составе методологии проектного офиса ФИПС можно условно выделить следующие этапы построения патентных ландшафтов:

$\rightarrow$ определение области охвата и границ патентного ландшафта;

$\rightarrow$ разработка модели предметной области;

$\rightarrow$ разработка поисковой стратегии и проведение поиска;

$\rightarrow$ контроль качества патентных коллекций;

$\rightarrow$ формирование аналитических представлений;

$\rightarrow$ экспертная интерпретация аналитических представлений;

$\rightarrow$ составление сводного отчета.

Далее в настоящем разделе представлено общее описание ключевых методологических аспектов по каждому из семи этапов.

\section{Определение области охвата и границ патентного ландшафта}

Данный этап является очень важным, так как, по сути, определяет необходимый уровень детали-
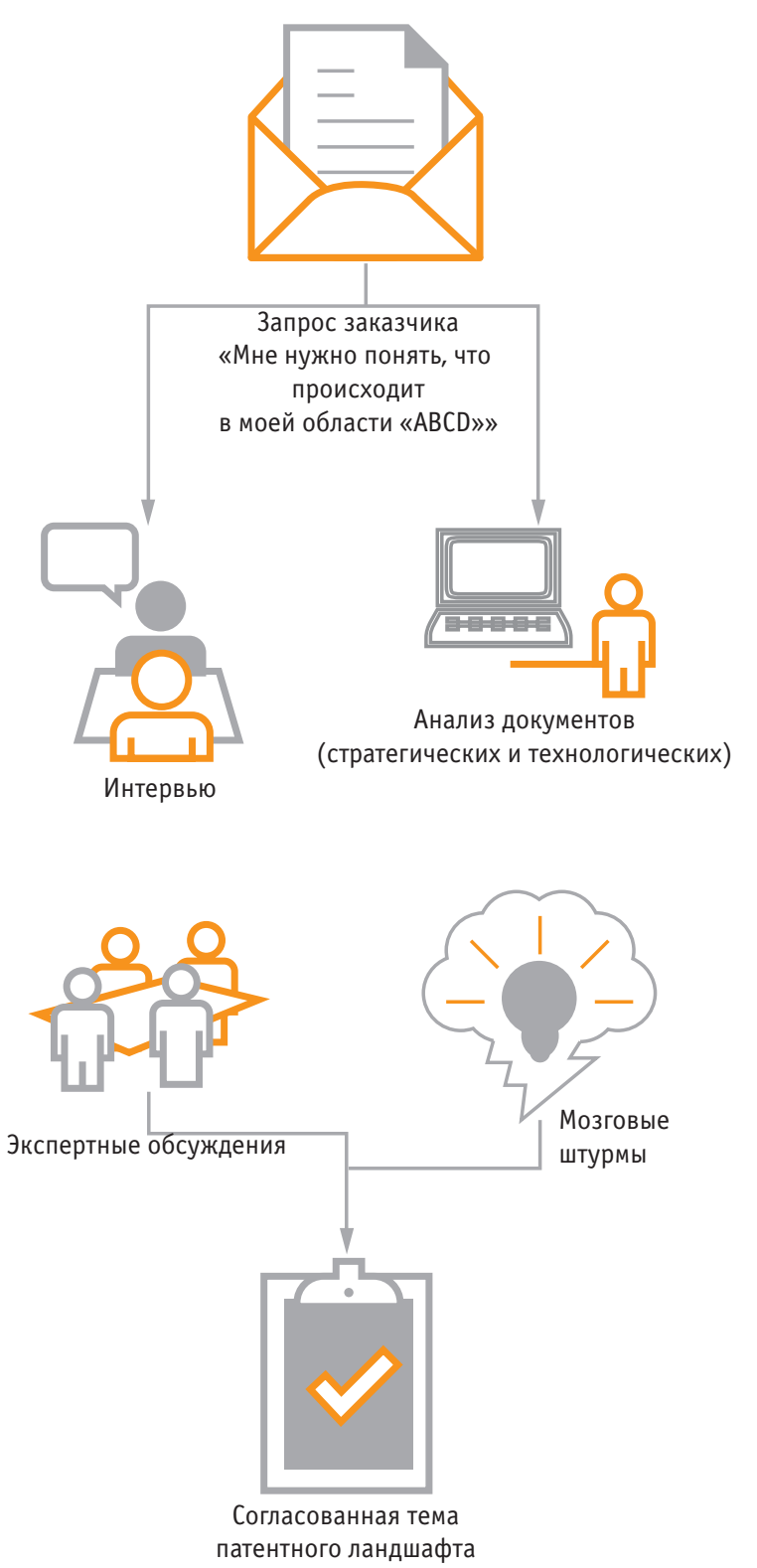

Puc. 1. Определение области охвата патентного ландшафта

зации предметной области. Излишне широкий охват патентного ландшафта влечет за собой снижение концентрации аналитических представлений важных для исследования технологических областей. В этом случае происходит слияние в модели патентного ландшафта технологических областей, для которых целесообразно выполнить технический анализ раздельно. Излишне узкий охват патентного ландшафта влечет за собой потерю технологических областей и/или ключевых аспектов, значимых для анализа предметной области.

Правильное определение границ патентного ландшафта обеспечивает включение в модель предметной области и последующую аналитическую 
обработку только тех технологических сегментов, которые необходимы и достаточны для выполнения анализа трендов, географии, стратегий, субъектов патентования, а также для выполнения углубленного технического анализа.

Методология ФИПС в части определения области охвата и границ патентного ландшафта предполагает организацию и проведение серии интервью, семинаров и мозговых штурмов, ориентированных на обсуждение содержания патентного ландшафта. В ходе подготовки к мозговым штурмам выполняется анализ документов как в области стратегического целеполагания, так и документов технологического содержания (технологические новости, блоги, планы исследований и разработок и пр.) (рис. 1).

В рамках экспертных обсуждений выполняется расширение / уточнение формулировки предметной области патентного ландшафта. В том числе важное значение имеет придание формулировке темы исследований всеобъемлющего характера, обеспечивающего максимально полный охват патентных документов.

\section{Модель предметной области}

Разработка модели предметной области - один из этапов в составе собственной методологии проектного офиса ФИПС - имеет критически важное значение. Полнота и консистентность модели предметной области, корректно выбранный подход

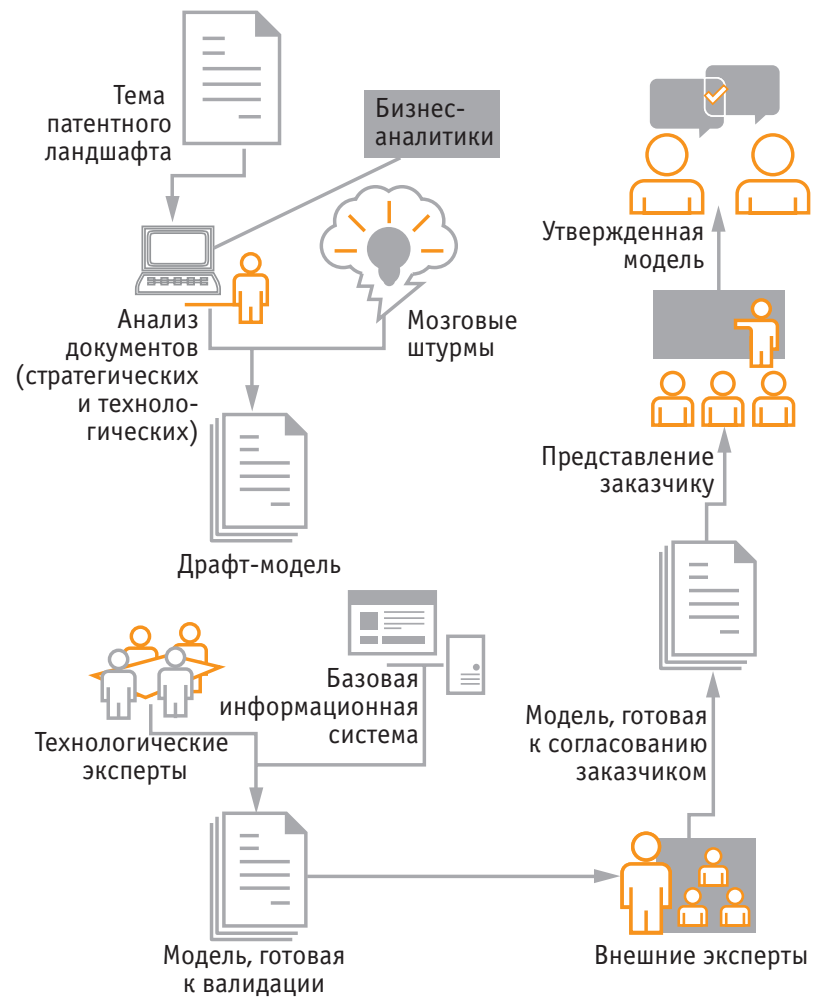

Puc. 2. Схема разработки модели предметной области к декомпозиции предметной области патентного ландшафта обеспечивают качество всего последующего анализа.

Методология разработки модели предметной области патентного ландшафта предусматривает три этапа разработки и согласования модели в ходе декомпозиции предметной области (рис. 2).

На первом этапе выполняется разработка проекта модели, включающего систему оснований (драфт-модель). Проект модели разрабатывается бизнес-аналитиками ФИПС и специалистами по формализации знаний. Также в разработке драфт-модели в целях всестороннего учета разнообразных аспектов анализа патентной информации участвуют специалисты ФИПС по глубинной патентной аналитике.

На первом этапе разработки модели предметной области выполняется кабинетное исследование патентной и непатентной литературы, а также проводится серия мозговых штурмов с участием бизнес-аналитиков и инженеров по знаниям.

На втором этапе выполняется доработка системы оснований модели предметной области и последующая декомпозиция каждого основания на составляющие его элементы. Второй этап выполняется силами отраслевых экспертов ФИПС, обладающих высокими компетенциями в предметной области патентного ландшафта. Результатом второго этапа работ является версия модели предметной области, готовая к согласованию заказчиком.

На третьем этапе выполняется согласование модели предметной области заказчиком. Согласование выполняется в ходе серии мозговых штурмов, на которых максимально подробно представляется структура и содержательное наполнение модели предметной области. Результатом третьего этапа является финальная модель предметной области, в контексте которой будет выполняться сбор, агрегация и анализ патентных данных.

\section{Разработка поисковой стратегии}

На данном этапе выполняется определение поисковой стратегии для сбора патентных документов и формирования генерализованной коллекции. В том числе определяются:

$\rightarrow$ источники патентной информации;

$\rightarrow$ глубина проведения патентных поисков;

$\rightarrow$ необходимость использования тематического, классификационного, нумерационного, именного поиска;

$\rightarrow$ правила группирования патентных семейств;

$\rightarrow$ языки, на которых осуществляется поиск;

$\rightarrow$ инструментальные средства, которые будут использованы для поиска;

$\rightarrow$ правила гармонизации и унификации патентной информации, полученной из разных систем; 


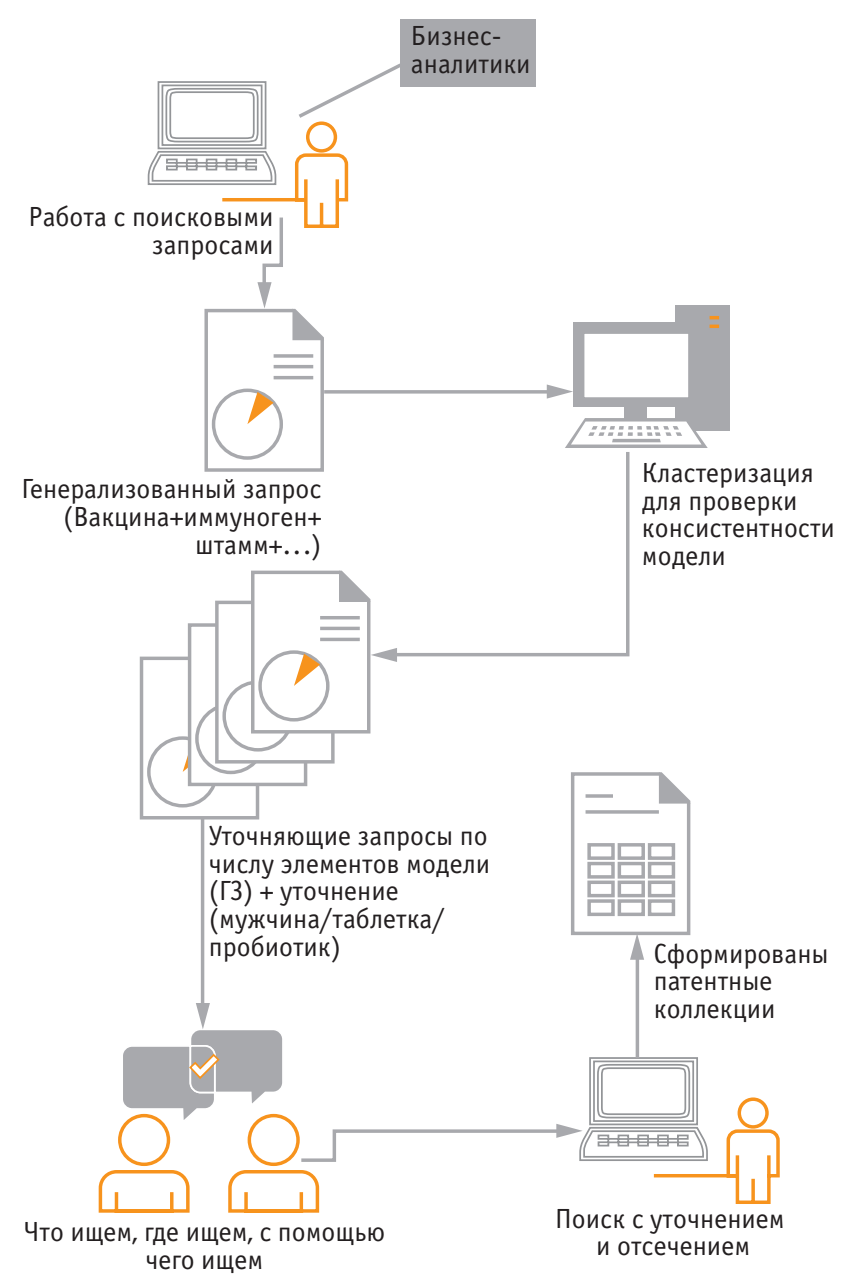

Puc. 3. Формирование поисковой стратегии

$\rightarrow$ необходимость использования специализированных видов поиска (поиск по формулам и др.).

Поисковая стратегия, как правило, предусматривает создание патентных пулов по классификационному поиску и тематическому поиску с последующим отсечением нерелевантных документов (рис. 3).

Особую роль при поиске с последующим анализом играют изменения названий, изменения организационно-правовых форм, слияния/поглощения компаний, технические ошибки патентных публикаций, которые могут возникать на этапе подготовки заявочных материалов заявителем, на этапах подготовки публикации в ведомстве, на этапах перегрузки библиографических данных во вторичные источники патентной документации. Отдельно следует отметить ошибки транслитерации, особенно существенные при анализе русскоязычных имен в англоязычных информационных системах. Важным моментом также является возможный переход прав (отчуждение) от одного патентовладельца к другому. Такой переход не будет отражен в исход- ной публикации, а возникает на последующих этапах правовой охраны. В полученной в результате поиска и уточнения информационной среде выделяют структурированные и неструктурированные данные, которые в дальнейшем анализируются сприменением различных фильтров, сортировок, систематизации, ограничений и т.п.

Результатом разработки поисковой стратегии является система поисковых запросов (генерализованный запрос для коллекции в целом и более 100 уточняющих запросов).

\section{Контроль качества патентных коллекций}

Данный этап является важным в контексте формирования генерализованной коллекции. Ценность аналитических представлений патентного ландшафта в значительной степени определяется качеством патентных документов и их метаданных. В целях обеспечения высокого качества формирования патентной коллекции для проведения анализа на первом этапе контроля качества выполняется отбраковка нерелевантных документов. Из-за высокой важности задач обеспечения релевантности документов отбраковка нерелевантных документов осуществляется в три этапа.

1. Первичный контроль релевантности с использованием автоматизированных средств. В рамках первичного контроля выполняется кластеризация генерализованной патентной коллекции и проводится анализ выявленных в ходе кластеризации технологических сегментов. На основании анализа технологических сегментов, не относящихся к предметной области патентного ландшафта, выполняется исключение нерелевантных патентных документов (путем модификации генерализованного поискового запроса).

2. Экспертный контроль релевантности генерализованной патентной коллекции. Для всех патентных документов, вошедших в генерализованную патентную коллекцию, выполняется ручная экспертиза соответствия документа предметной области патентного ландшафта. Для проведения экспертизы задействуются команды патентных экспертов ФИПС, обладающих высокими компетенциями в экспертизе патентных документов данной тематики. В качестве инструмента для отбраковки нерелевантных документов используется система профессионального патентного поиска и экспертизы PatSearch (собственное программное обеспечение ФИПС).

3. Экспертный контроль релевантности уточняющих патентных коллекций. Данный этап является наиболее ресурсоемким, так как предполагает детальный анализ релевантности патентных документов для каждого из элементов модели предметной области. 


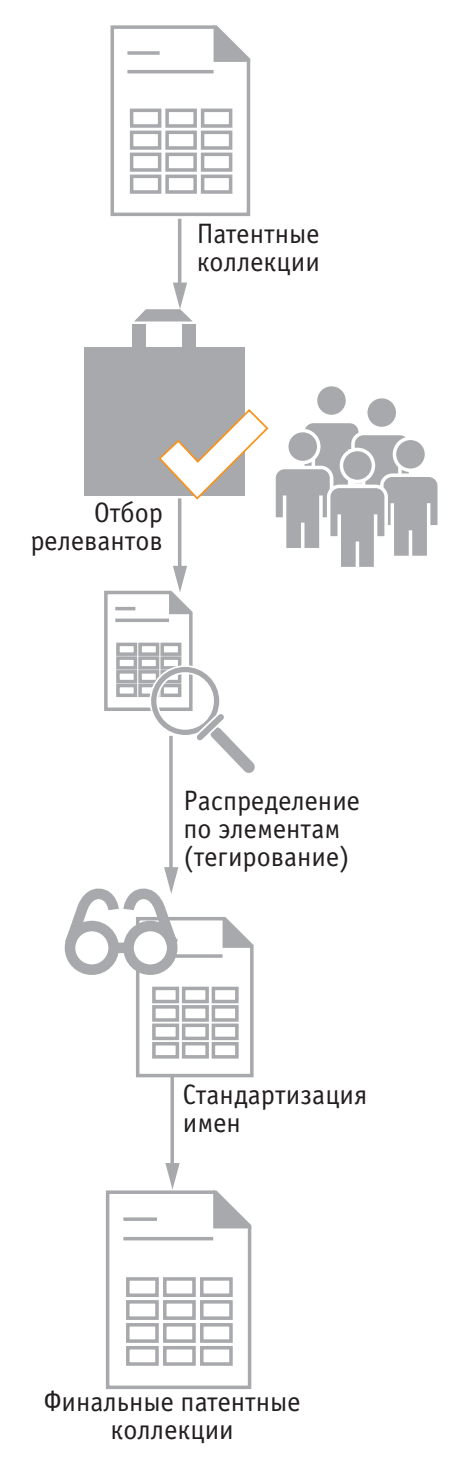
ства патентных коллекций
Puc. 4. Схема контроля каче-

После отбраковки нерелевантных документов выполняется стандартизация названий организацийпатентовладельцев и фамилий авторов и 3 о бр е те ни й . В качестве инструм е н т а л ь н ы х средств для выполнения стандартизации используются внешние инструменты патентной аналитики, а также собственное программное обеспечение проектного офиса ФИПС, специально разработанное для решения задач стандартизации.

К л ю ч е в ы м результатом контроля качества патентной коллекции является релевантная генерализованная патентная коллекция, а также реестры стандартизованных названий организаций-патентовладельцев и авторов изобретений (рис. 4).

Формирование аналитических представлений

На данном этапе выполняется формирование аналитических представлений для каждого из разделов патентного ландшафта:

$\rightarrow$ тренды;

$\rightarrow$ стратегии патентования;

$\rightarrow$ география;

$\rightarrow$ субъекты (компании и люди);

$\rightarrow$ анализ патентного цитирования;

$\rightarrow$ правовые события;

$\rightarrow$ технический анализ.

В качестве инструментальных средств для формирования аналитических представлений используется весь набор программных систем патентной аналитики, как разрабатываемых ФИПС, так и внешних систем патентной аналитики ведущих производителей.

\section{Экспертная интерпретация аналитических представлений}

Данный этап является важным, так как комплексная экспертная интерпретация вносит наибольший вклад в практическую ценность отчета о патентном ландшафте. Для экспертной интерпретации аналитических представлений привлекаются три группы экспертов (многоуровневая экспертная интерпретация):

$\rightarrow$ бизнес-аналитики и специалисты по углубленной патентной аналитике;

$\rightarrow$ отраслевые патентные эксперты ФИПС;

$\rightarrow$ внешние высококвалифицированные отраслевые эксперты, ведущие отраслевые компании и инжиниринговые центры.

Привлечение трех групп экспертов связано с необходимостью обеспечения комплексного анализа сложных аналитических представлений, учитывающих разнообразные аспекты технологического развития и вывода на рынки продуктов и услуг в предметной области патентного ландшафта, а также учета при разработке патентного ландшафта стратегических отраслевых документов, долгосрочных планов развития отрасли и других документов, определяющих цели и ключевые направления развития предметной области.

\section{Составление сводного отчета}

При составлении отчета о патентном ландшафте наибольшее значение имеет ориентация на Заказчика. Пакет материалов, передаваемый Исполнителем Заказчику по результатам построения патентного ландшафта, помимо самого ландшафта, может включать краткое сводное резюме исследования; базы данных выгруженных патентов, попавших в анализ; приложения с визуализацией, не вошедшие в основной отчет, например, из-за нестандартного формата; таблицы, на основе которых созданы диаграммы и другие объекты визуализации; приложения с указанием поисковых запросов, если это необходимо заказчику; перечень принятых определений и сокращений и др.

\section{ОСОБЕННОСТИ ЭКСПРЕСС ПАТЕНТНЫХ ЛАНДШАФТОВ ПРОЕКТНОГО ОФИСА ФИПС. ОБЩИЕ ПОЛОЖЕНИЯ}

Экспресс патентные ландшафты являются эффективным инструментом анализа трендов технологического развития в сфере интересов компании-заказчика. Важной отличительной особенностью экспресс патентных ландшафтов ФИПС является сочетание комплексного представления 
разнообразных аспектов (тренды, география, компании и люди, рынки/области применения) и специфики разработки ландшафтов в концепции «ключевые инсайты». Данная концепция предполагает выявление аномалий или устойчивых паттернов на всех видах аналитических представлений и, в дальнейшем, дополнительный углубленный анализ в отношении каждого выявленного паттерна (аномалии). Такой подход исследования, управляемого аналитикой (analytics-driven), обеспечивает максимально полный охват в отношении наиболее выразительных и характерных особенностей патентования в конкретном технологическом сегменте (например, нехарактерно высокий/низкий процент выданных патентов, превышение силы патентов над среднестатистическими значениями и др.).

Экспресс патентные ландшафты, разработанные в таком сочетании техник и методов, являются полезным аналитическим инструментом для поиска лучших современных технологий и продуктов в области интересов Заказчика, выявления фокусов технологического внимания отраслевых компанийлидеров и анализа появления новых рынков (областей применения) продукции.

Структура патентного ландшафта включает в себя разделы, которые позволяют оценить развитие исследуемой технологической области:

$\rightarrow$ тренды патентования;

$\rightarrow$ компании и люди;

$\rightarrow$ география;

$\rightarrow$ рынки / области применения.

Для каждого из представленных выше разделов формируется набор аналитических представлений, при помощи которых могут быть выявлены закономерности и ключевые этапы развития исследуемой области, а также нехарактерные для нее явления, требующие особого внимания.

Формирование аналитических представлений выполняется с использованием широкого набора инструментальных средств, среди которых как собственные программные системы ФИПС (включая систему профессионального патентного поиска PatSearch), так и системы патентной аналитики ведущих зарубежных поставщиков (Clarivate Analytics Derwent Innovation, LexisNexis PatentStrategies, Questel Orbit Platinum Edition и др.). Применение различных инструментов обеспечивает наиболее полную номенклатуру наглядных аналитических представлений, характеризующих разнообразные аспекты развития области.

В качестве информационной основы для аналитических представлений выступают:

$\rightarrow$ проверенные на соответствие области патентные коллекции; $\rightarrow$ реестры стандартизованных названий компаний-патентообладателей и имен авторов изобретений;

$\rightarrow$ коды МПК;

$\rightarrow$ коды вида документа;

$\rightarrow$ коды стран, в которых зарегистрированы документы (страна первой подачи и последующих подач, страна приоритета);

$\rightarrow$ даты подачи заявки, публикации патентного документа и приоритета;

$\rightarrow$ поля, указывающие на правовые события (патентные споры, случаи лицензирования и др.).

В наборе аналитических представлений, формируемых для каждого раздела, присутствуют стандартные представления и введенные специально в рамках конкретного исследования, которые призваны раскрыть присущие ей уникальные тенденции и явления. Среди них, например, структура портфеля отдельных компаний, соотношение в области полезных моделей и изобретений и т.д.

В качестве информационной основы и набора показателей при разработке экспресс патентных ландшафтов используются разнообразные показатели, характеризующие даты ключевых событий, связанных с жизненным циклом патентов. Наиболее распространенные виды анализа связаны с датами подачи заявки, определения наиболее раннего приоритета и выдачи патента. Соотнесение указанных дат позволяет определить периоды разработки технических решений, а также длительность циклов улучшения, доработки патентных документов до выпуска патента.

Важным направлением исследования является сопоставление четырех взаимоувязанных показателей, характеризующих особенности патентования предметной области: патенты, патентные заявки, приоритеты и патентные семейства. Такое комбинированное сопоставление обеспечивает широкий набор видов анализа в интересах оценки уровня зрелости технологий, появления более комплексных продуктов, выявления масштабного захвата компаниями перспективных областей патентования и т.д.

Особое место в составе экспресс патентного ландшафта занимает анализ позиций России (СССР для более ранних периодов) относительно позиций зарубежных стран. Такой вид анализа позволяет исследовать временные периоды, в которых высока доля российских изобретений и выявить отечественные исследовательские и производственные коллективы и физических лиц, владеющих техническими решениями с высоким уровнем технической новизны.

При анализе субъектов патентования выявляются и анализируются наиболее активные изобретатели и патентообладатели - лидеры области. На основании полученных данных можно 


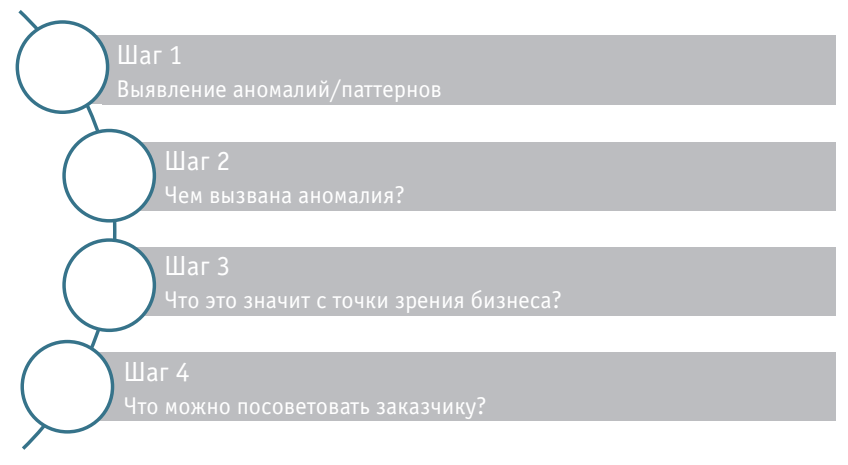

Puc. 5. Схема выявления и интерпретации аномалий и паттернов

сделать выводы о предполагаемых партнерах и конкурентах.

В качестве информационной основы для исследования географии патентования используются сведения о территориальной принадлежности патентуемых технических решений. В качестве основного показателя при анализе географии преимущественно используется страна публикации. Так, анализ страны первой подачи патента в большей степени характеризует место происхождения изобретения, а анализ стран последующих подач в большей степени характеризует перспективные рынки (потенциально привлекательные центры производства).

Помимо этого, анализ в разрезе стран-лидеров в комбинации с анализом субъектов патентования и патентного цитирования позволяет выявить и в дальнейшем более детально проанализировать области компетенций национальных и межнациональных исследовательских коллективов в перспективных технологических сегментах патентного ландшафта.

Важным результатом работ в рамках каждого экспресс патентного ландшафта является многоуровневое формирование выводов, включая выявление аномалий / паттернов, формирование гипотез и исследование причин появления аномалий, интерпретация аномалий с точки зрения бизнеса и формирование конкретных рекомендаций заказчику по реагированию на выявленные тенденции (рис. 5).

Многоуровневое формирование выводов в рамках экспресс патентного ландшафта выполняется в ходе трех этапов.

1. Первичный анализ графиков, диаграмм и других форм аналитических представлений - описания характерных тенденций, выявленных в ходе анализа, приводятся непосредственно после представлений.

2. Контекстные выводы бизнес-направленности. Представляют собой краткий вывод, основан- ный на экспертном анализе, сопоставлении и интерпретации аналитических представлений с точки зрения бизнеса, стратегий и тактик патентования мировых компаний-лидеров.

3. Наиболее важные выводы, полученные в ходе предыдущих этапов анализа, сводятся в итоговую таблицу в разделе «Заключение» экспресс патентного ландшафта. Выводы ранжируются по четырем категориям: «Стратегии компанийлидеров», «Перспективные рынки», «Технологические приоритеты», «Позиции России». По каждому выводу дается рекомендация заказчику по реагированию и адаптации стратегии технологического развития в соответствии с выявленными тенденциями мирового технологического развития.

\section{ЗАКЛЮЧЕНИЕ}

Патентные ландшафты зарекомендовали себя на российском и мировом уровнях как комплексный и многопрофильный инструмент определения научно-технологических приоритетов и исследования конкурентоспособности перспективных технологий, продуктов и сервисов, предполагаемых к выводу продукции на ключевые рынки.

Системное и массовое применение методологии разработки отраслевых и экспресс патентных ландшафтов, представленной в настоящей статье, обеспечит формирование эффективной инфраструктуры экспертно-аналитической поддержки новых инструментов корпоративной и государственной политики развития новых индустрий и координации перспективных технологических проектов, а также формирование принципиально новых рынков и создание условий для глобального технологического лидерства России.

\section{ЛИТЕРАТУРА}

1. Guidelines for Preparing Patent Landscape Reports prepared for the WIPO by Anthony Trippe, Patinformatics, LLC, 2015 http://www.wipo.int/ edocs/pubdocs/en/wipo_pub_946.pdf

2. Методические рекомендации по подготовке отчетов о патентном обзоре (патентный ландшафт). М.: ФИПС, 2017. 16 с.

\footnotetext{
ЕНА Олег Валерьевич руководитель проектного офиса Федерального института промышленной собственности
}

попов Николай Васильевич -

заместитель руководителя проектного офиса Федерального института промышленной собственности 